\title{
Assessment of the relation between initial culprit vessel patency in acute ST-elevation myocardial infarction and endothelial function
}

Jasveen J. Kandhai-Ragunath ${ }^{1}$, MD; Harald T. Jørstad², MD, MSc; Bjorn de Wagenaar ${ }^{3}$, MSc;

Frits H.A.F. de Man $^{1}$, MD, PhD; Martin G. Stoel ${ }^{1}$, MD, PhD; Jan van Es ${ }^{1}$, MD;

Cees J.A. Doelman ${ }^{4}$, MBA, PhD; Carine J.M. Doggen ${ }^{\text {, }}$ PhD; Ron J.G. Peters ${ }^{2}, \mathrm{MD}$, PhD;

Clemens von Birgelen ${ }^{1 *}, \mathrm{MD}, \mathrm{PhD}$

1. Department of Cardiology, Thoraxcentrum Twente, Medisch Spectrum Twente, Enschede, The Netherlands; 2. Academisch Medisch Centrum, Amsterdam, The Netherlands; 3. MESA, Institute for Nanotechnology, University of Twente, Enschede, The Netherlands; 4. Medlon Laboratory Diagnostics, Medisch Spectrum Twente, Enschede, The Netherlands; 5. Health Technology and Services Research, MIRA - Institute for Biomedical Technology and Technical Medicine, University of Twente, Enschede, The Netherlands

KEYWORDS
- coronary artery
disease
- culprit vessel
patency
- endothelial
function
- myocardial
infarction
- reactive
hyperaemia
peripheral artery
tonometry
- ST-elevation
myocardial
infarction

\begin{abstract}
Aims: To assess whether better endothelial function increases the likelihood of patients with acute ST-elevation myocardial infarction (STEMI) having initially patent culprit vessels. Clinical data on the relation between endothelial function and culprit vessel patency in STEMI patients are scarce.

Methods and results: In this prospective cohort study in 71 patients with STEMI, endothelial function was non-invasively assessed by use of the reactive hyperaemia peripheral artery tonometry (RH-PAT) method at four to six weeks after the primary percutaneous coronary intervention (PPCI). The RH-PAT index measured on average $1.90 \pm 0.58$. In patients with patent culprit vessels before PPCI ( $n=33,46.5 \%$ ), endothelial function was significantly better than in patients with occluded vessels $(n=38,53.5 \%)$ (RH-PAT index $2.08 \pm 0.34$ vs. $1.75 \pm 0.35 ; \mathrm{p}<0.007)$. Compared to patients with normal endothelial function, the patients with severe endothelial dysfunction had a fivefold higher risk of presenting with an occluded culprit vessel (OR 5.1, 95\% CI: 1.8-14.2). Logistic regression analysis revealed that this relation between endothelial function and vessel patency became even stronger after adjustment for potential confounders (adjusted OR 7.1, 95\% CI: 2.1-23.6).
\end{abstract}

Conclusions: In this series of patients with acute STEMI, better endothelial function was independently associated with a higher likelihood of presenting with an initially patent culprit vessel.

*Corresponding author: Department of Cardiology, Thoraxcentrum Twente, Medisch Spectrum Twente, Haaksbergerstraat 55 , 7513 ER Enschede, The Netherlands.E-mail: c.vonbirgelen@mst.nl 


\section{Abbreviations}

$\begin{array}{ll}\text { CI } & \text { confidence interval } \\ \text { OR } & \text { odds ratio } \\ \text { PPCI } & \text { primary percutaneous coronary intervention } \\ \text { RH-PAT } & \text { reactive hyperaemia peripheral artery tonometry } \\ \text { SD } & \text { standard deviation } \\ \text { STEMI } & \text { ST-elevation myocardial infarction }\end{array}$

\section{Introduction}

During primary percutaneous coronary intervention (PPCI), patients with acute ST-elevation myocardial infarction (STEMI) initially present with either a patent or an occluded culprit vessel. Patency of the infarct-related artery at presentation can lead to a more favourable clinical course, with an initial TIMI flow grade 2 or 3 being the main predictor ${ }^{1}$. The coronary endothelium may play a major role in the process of restoring coronary patency and flow, as it modulates vascular tone by the release of various substances to control perfusion and regulate platelet aggregation ${ }^{2-4}$. As a consequence, STEMI patients with better endothelial function might have a higher chance of early culprit vessel patency.

Non-invasive techniques have been developed to measure peripheral endothelial function, which has been shown to correlate well with coronary endothelial function ${ }^{5,6}$. While ultrasound-based methods for the measurement of flow-mediated dilatation of the brachial artery require training and experience to provide reliable and reproducible data on endothelial function, reactive hyperaemia peripheral artery tonometry (RH-PAT) is an operator-independent method that has previously been validated against measurements of flow-mediated dilatation of the brachial artery ${ }^{7,8}$. In addition, it has previously been shown with RH-PAT that peripheral endothelial function is reduced in patients with proven coronary endothelial dysfunction 9 . In the present study, we used RH-PAT in STEMI patients to investigate whether a better endothelial function increases the likelihood of initial coronary vessel patency.

\section{Methods}

\section{STUDY DESIGN AND PATIENT POPULATION}

In this prospective observational study, we assessed a series of 71 patients with STEMI, who were treated by PPCI $(\leq 12$ hours after symptom onset) and underwent non-invasive RH-PAT assessment between October 2007 and December 2008 at Thoraxcentrum Twente in Enschede. The study population represents all STEMI patients of the RESPONSE (Randomised Evaluation of Secondary Prevention by Outpatient Nurse SpEcialists) trial ${ }^{10}$, who were enrolled at Thoraxcentrum Twente and agreed to participate in this substudy. Patients were eligible for enrolment if they were between 18 and 80 years of age, were available for and willing to adhere to the follow-up procedures, had no surgery or additional PCI planned within eight weeks from PPCI, and had a life expectancy of at least two years in the absence of heart failure NYHA Class III or IV. Our study population was 71 patients with STEMI, while four patients were excluded from the analysis because the initial coronary flow was not documented or RH-PAT measurements were not valid.
As inflammation and repair processes of the infarcted myocardium might have disturbed endothelial function during the first weeks after the STEMI, endothelial function was assessed four to six weeks later. The patients were seen in the outpatient clinic and the research department of Thoraxcentrum Twente, where noninvasive assessment of the endothelial function was performed according to strict rules in a dedicated laboratory. All patients provided written informed consent for participation in the study. The study complied with the Declaration of Helsinki for investigation in human beings and was approved by the Medical Ethical Committee Twente in Enschede, The Netherlands.

\section{INTERVENTIONAL PROCEDURE AND ANGIOGRAPHIC EVALUATION OF VESSEL PATENCY}

All patients were treated prior to admission in the ambulance with an intravenous bolus of 5,000 IU of unfractionated heparin, a loading dose of at least $300 \mathrm{mg}$ of acetylsalicylic acid (orally or intravenously), and an oral loading dose of $600 \mathrm{mg}$ of clopidogrel. In most patients ( $n=46,64.8 \%$ ), a weight-adjusted intracoronary bolus of abciximab was administered in the catheterisation laboratory, but never before visualising the culprit coronary artery to assess vessel anatomy and patency. In brief, procedures were performed through femoral or radial access routes via 6 Fr sheaths. Pharmacological therapy before, during, and after the interventional procedure, use of aspiration catheters, lesion preparation (vs. direct stenting), and stent post-dilatation were performed according to current guidelines and the operators' judgement and discretion (Table 1). In all patients, flow characteristics and patency of the culprit vessel were documented prior to any mechanical intervention or administration of a glycoprotein IIb/ IIIa inhibitor. An angiographic evaluation committee consisting of at least three experienced cardiologists assessed the TIMI flow grade of the culprit coronary vessels. Patency of the culprit vessel was considered if the angiographic evaluation committee scored a TIMI flow grade 2 or 3; in contrast, an occluded culprit vessel was defined as a vessel with TIMI flow grade 0 or $1^{11,12}$. Members of the committee were blinded for the outcome of the RH-PAT measurements.

\section{NON-INVASIVE ASSESSMENT OF ENDOTHELIAL FUNCTION}

The RH-PAT method was applied to assess endothelial function by assessing the finger pulse wave amplitude with the EndoPAT ${ }^{\mathrm{TM}}$ 2000 sensing device and finger plethysmographic probes (Itamar Medical Ltd., Caesarea, Israel), both at baseline and during ischaemia-induced hyperaemia. All examinations were performed in a dedicated laboratory. Measurements were performed in the morning after a fasting period of at least eight hours. Patients also had to refrain from smoking, caffeine consumption, and vasoactive medications. At least 15 minutes before testing, blood pressure was measured and a blood sample was drawn in the control arm. Before measurements were performed, patients had an acclimatisation period of 20 minutes in a quiet room, lying in a hospital bed at an ambient temperature of $21-23^{\circ} \mathrm{C}$. 
Table 1. Demographics, procedural details, and early outcome of the entire study population.

\begin{tabular}{|c|c|c|c|c|c|}
\hline \multicolumn{3}{|c|}{ Demographics and characteristics of all patients $(n=71)$} & \multicolumn{3}{|c|}{ Coronary angiographic data and details of the interventional procedure $(n=71)$} \\
\hline \multicolumn{2}{|l|}{ Men } & $55(77.5)$ & \multicolumn{2}{|c|}{ Thrombus aspiration performed** } & $38(53.5)$ \\
\hline \multicolumn{2}{|c|}{ Age (years), mean (SD), range } & $56.7(9.3), 38-76$ & \multicolumn{2}{|l|}{ Direct stenting performed } & $36(50.7)$ \\
\hline \multicolumn{2}{|l|}{ Current smoker } & $29(40.8)$ & \multicolumn{2}{|l|}{ Post-dilatation performed } & $56(78.9)$ \\
\hline \multicolumn{2}{|l|}{ Diabetes } & $10(14.1)$ & \multicolumn{2}{|c|}{ Maximum inflation pressure (atm), mean (SD), range } & $15.9(2.5), 8-20$ \\
\hline \multicolumn{2}{|l|}{ Hypercholesterolaemia } & $17(23.9)$ & \multicolumn{2}{|c|}{ Total stent length $(\mathrm{mm})$, mean $(\mathrm{SD})$, range } & $34.1(23.8), 13-132$ \\
\hline \multicolumn{2}{|l|}{ Hypertension } & $19(26.8)$ & \multirow{4}{*}{$\begin{array}{l}\text { TIMI flow grade after } \\
\text { PPCI (final) }\end{array}$} & 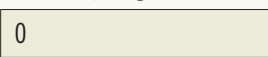 & $1(1.4)$ \\
\hline \multicolumn{2}{|c|}{ BMI $\left(\mathrm{kg} / \mathrm{m}^{2}\right)$, mean (SD), range } & $28.4(4.3), 21.0-51.0$ & & 1 & $0(0)$ \\
\hline \multicolumn{2}{|c|}{ History of $\mathrm{PCl}$} & $8(11.3)$ & & 2 & $2(2.8)$ \\
\hline \multicolumn{2}{|c|}{ History of CABG } & $1(1.4)$ & & 3 & $68(95.8)$ \\
\hline \multicolumn{3}{|c|}{ Coronary angiographic data and details of the interventional procedure $(n=71)$} & \multirow{4}{*}{$\begin{array}{l}\text { Myocardial blush grade } \\
\text { after PPCI (final) }\end{array}$} & 0 & $2(2.8)$ \\
\hline \multicolumn{2}{|c|}{ PPCl through femoral route* } & $65(98.5)$ & & 1 & $2(2.8)$ \\
\hline \multicolumn{2}{|c|}{ Systolic blood pressure during PPCI (mmHg), mean (SD), range } & $124.8(24.3), 60-170$ & & 2 & $7(9.9)$ \\
\hline \multicolumn{2}{|c|}{ Diastolic blood pressure during PPCI (mmHg), mean (SD), range } & $76.6(14.6), 35-110$ & & 3 & $60(84.5)$ \\
\hline \multicolumn{2}{|c|}{ Heart rate during PPCI (beats/min), mean (SD), range } & 73.8 (17.8), $46-115$ & \multirow{2}{*}{\multicolumn{3}{|c|}{$\begin{array}{l}\text { Cardiac marker release, residual left ventricular function, and heart failure } \\
\qquad(\mathrm{n}=71)\end{array}$}} \\
\hline \multirow[t]{3}{*}{ Vessel disease* } & 1 & $52(74.3)$ & & & \\
\hline & 2 & $15(21.4)$ & \multirow{4}{*}{$\begin{array}{l}\text { Maximum creatine } \\
\text { kinase level }(\mathrm{IU} / \mathrm{L})^{*}\end{array}$} & $<500$ & $24(33.8)$ \\
\hline & 3 & $3(4.3)$ & & $500-1,000$ & $16(23.9)$ \\
\hline \multirow[t]{3}{*}{ Culprit vessel } & Right coronary artery & $31(43.7)$ & & $1,000-2,000$ & $14(19.8)$ \\
\hline & Left anterior descending artery & $29(40.8)$ & & $>2,000$ & $16(22.5)$ \\
\hline & Circumflex artery & $9(12.7)$ & \multirow{3}{*}{$\begin{array}{l}\text { Left ventricular ejection } \\
\text { fraction } \\
\text { (echocardiography) }\end{array}$} & $>50 \%$ & $64(90.1)$ \\
\hline \multicolumn{2}{|c|}{ Multivessel PPCI (left main/left coronary artery/circumflex artery) } & $1(1.4)$ & & $40-50 \%$ & $7(9.9)$ \\
\hline \multirow{4}{*}{$\begin{array}{l}\text { TIMI flow grade before } \\
\text { PPCI (initial) }\end{array}$} & 0 & $32(45.1)$ & & $<40 \%$ & $0(0)$ \\
\hline & 1 & $6(8.5)$ & \multirow{4}{*}{$\begin{array}{l}\text { Heart failure symptoms } \\
\text { (NYHA class) }\end{array}$} & I & $67(94.4)$ \\
\hline & 2 & $17(23.9)$ & & II & $4(5.6)$ \\
\hline & 3 & $16(22.5)$ & & III & $0(0)$ \\
\hline Myocardial blush grade & 0 & $47(66.2)$ & & IV & $0(0)$ \\
\hline before PPCI (initial) & 1 & $11(15.5)$ & Haemodynamics & during endothelial funct & surement $(n=71)$ \\
\hline & 2 & $13(18.3)$ & Systolic blood pressure (n & $\mathrm{nmHg}$ ), mean (SD), range & $132.6(14.7), 130.7-134.6$ \\
\hline & 3 & $0(0)$ & Diastolic blood pressure ( & $(\mathrm{mmHg})$, mean $(\mathrm{SD})$, range & $81.8(11), 80.3-83.3$ \\
\hline Thrombus visible on ang & ggraphy & $35(49.3)$ & Heart rate (beats/min), $\mathrm{m}$ & ean (SD), range & $64(10.7), 63-65.8$ \\
\hline
\end{tabular}

Data are $n(\%)$ unless otherwise specified. ${ }^{*} \leq 5$ missing values, ${ }^{* *}=6-10$ missing values. BMI: body mass index; CABG: coronary artery bypass grafting; NYHA: New York Heart Association; PPCl: primary percutaneous coronary intervention; SD: standard deviation; TIMI: Thrombolysis In Myocardial Infarction

With an inflatable finger cuff, the vasculature of the distal segment of the index finger was compressed to avoid blood pooling and to ensure even distribution of pressure along that segment (study arm). To control for systemic effects, a cuff was placed on the contralateral finger experiencing no hyperaemia (control arm). Probes on the index fingers of both hands (study and control arm) were inflated to a pressure of $10 \mathrm{mmHg}$ below the diastolic pressure, while sensors, integrated in the cuffs, continuously recorded pressures in both fingers. After an acclimatisation period of 10 minutes, baseline measurements were recorded during five minutes prior to inducing ischaemia. A blood pressure cuff on the upper arm (study arm) was inflated for five minutes to suprasystolic pressures, leading to nitric oxide (NO) release from functional endothelium and thus to vasodilatation that was recorded by the sensors in the finger cuff through beat-to-beat finger pulsed wave analysis. After release of the blood pressure cuff from the upper arm (study arm), the ratio of the pulse amplitude of the hyperaemic finger to baseline amplitude was calculated for 30-second intervals. Subsequently, that ratio was divided by the corresponding ratio obtained in the control arm to calculate the RH-PAT index (Figure 1) ${ }^{13}$. As a consequence, higher values of the RH-PAT index indicated better endothelial function. An endothelial function of $<1.67$ was defined as a bad endothelial function and used in the forthcoming analyses ${ }^{14}$.

Recently, Hamburg et $\mathrm{al}^{15}$ demonstrated that the maximum hyperaemic response can be expected 90 to 120 seconds after cuff deflation. Therefore, in the present study, the reactive RH-PAT index was calculated as the ratio of the mean hyperaemic pulsed wave analysis over a period of 30 seconds, beginning at 90 seconds after cuff deflation, divided by the baseline pulsed wave analysis (mean baseline measurements during 3.5 minutes), and normalised to the 


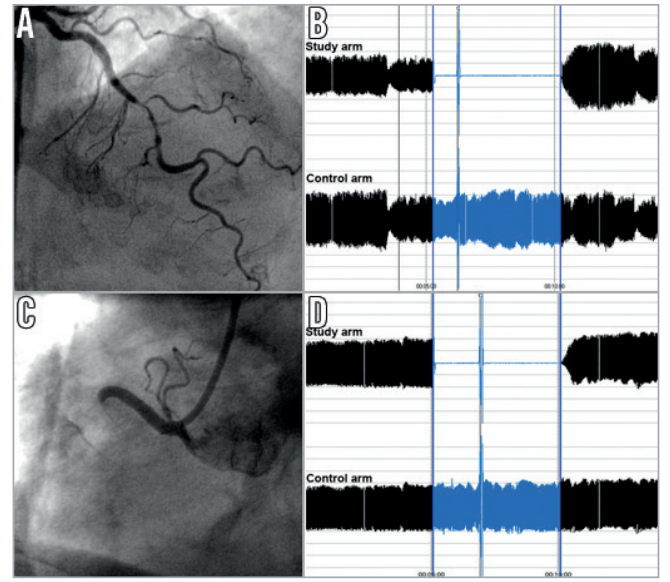

Figure 1. Examples of coronary angiography at presentation and endothelial function measurements in two patients with single-vessel disease. In the first case (A,B), a 66-year-old male with acute anterior STEMI presented with initially subtotal but patent mid LAD lesion (A). Four weeks after primary PCI, endothelial function was assessed with the reactive hyperaemia peripheral artery tonometry (RH-PAT) method. Pressure recordings from study and control arm during baseline, cuff inflation on the study arm, and post-ischaemic hyperaemia (left to right) were used to calculate the RH-PAT index. The RH-PAT index of 2.51 indicated a favourable endothelial function in this patient, who had initially presented with a patent culprit vessel. The panels of the second case (C,D) show the coronary angiography at presentation $(C)$ and RH-PAT measurements (D) of a 45-year-old male with an acute inferior STEMI. In this patient who had initially presented with an occluded proximal RCA, the RH-PAT index of 1.48 indicated a diminished endothelial function.

concurrent measurements of the control arm. Several studies demonstrated good reproducibility of the RH-PAT index, even when performed on different days ${ }^{16,17}$.

\section{Patient characteristics used for analyses}

The following information was documented: age; sex; body mass index (BMI, $\mathrm{kg} / \mathrm{m}^{2}$ ); arterial hypertension (blood pressure of $>140 / 90 \mathrm{mmHg}$ or treatment with antihypertensive medication); smoking history (previous or current smoker); history of previous myocardial infarction and/or coronary revascularisation by means of percutaneous coronary intervention or bypass surgery; time from symptom onset to PPCI; presence of diabetes mellitus (patient history and/or treatment with insulin or oral antiglycaemic agents); and history of hyperlipidaemia or treatment with lipid-lowering drugs.

\section{STATISTICAL ANALYSIS}

All analyses were performed with SPSS version 16.0 (SPSS Inc., Chicago, IL, USA). We used the $\chi^{2}$ test for categorical variables, and t-test or analysis of variance for continuous variables to compare patients presenting with a patent culprit vessel versus patients with an occluded culprit vessel, as appropriate. Pearson correlations were calculated for the association between a continuous variable and RH-PAT. Data are presented as mean \pm standard deviation (SD) with a $95 \%$ confidence interval (CI) or as frequencies. A p-value $<0.05$ was considered statistically significant. Variables that might have an influence on vessel patency and RH-PAT measurements were identified based on $p$-values $\leq 0.2$, and subjected to an unconditional logistic regression. Quintiles of RH-PAT index were assessed, based on the overall group of patients. Odds ratios (OR) were calculated with the lowest quintile as the reference group, with the appropriate $95 \%$ confidence interval.

\section{Results \\ DEMOGRAPHICS, INTERVENTIONAL PROCEDURE, AND CLINICAL COURSE}

The study population consisted of 71 patients, of whom 55 (77.5\%) were men. Further demographics and characteristics of the procedure are presented in Table 1. Of the study population, 65 patients (98.5\%) had the PPCI performed via the femoral route. Prior to PPCI, 38 (53.5\%) patients had a TIMI flow grade 0 or 1 in the culprit vessel, while $33(46.5 \%)$ patients had a patent vessel with an initial TIMI flow grade of 2 or 3 . Thrombus aspiration was performed in $38(53.5 \%)$ patients, direct stenting in $36(50.7 \%)$, and stent post-dilatation in 56 (78.9\%). Following PPCI, 68 (95.8\%) patients had a TIMI flow grade 3, and only one patient had TIMI flow grade $0(1.4 \%)$. At discharge, most patients had a left ventricular ejection fraction $>50 \%(n=64,90.1 \%)$ without symptoms of heart failure $(n=67,94.4 \%)$.

\section{PATIENTS WITH PATENT VERSUS OCCLUDED CULPRIT VESSELS AT PRESENTATION}

Based on the initial culprit vessel patency at presentation prior to any mechanical intervention or the administration of a glycoprotein IIb/IIIa inhibitor, patients were subdivided into patients with patent $(n=33,46.5 \%)$ versus occluded vessels $(n=38,53.5 \%)$. Both groups did not differ in age or other cardiovascular risk factors (Table 2). Time from symptom onset to PPCI was on average $163 \pm 55$ minutes and did not differ significantly between patients with patent versus occluded culprit vessels (185 \pm 114 vs. $149 \pm 54 \mathrm{~min} ; \mathrm{p}=0.20$ ). The size of the myocardial infarction, as measured by the maximum creatine kinase levels, was similar for patients with patent versus occluded culprit vessels (1,187 \pm 855 vs. $1,387 \pm 870 \mathrm{IU} / \mathrm{L} ; \mathrm{p}=0.51$ ). There was no difference in left ventricular ejection fraction between patients with patent versus occluded culprit vessels. In most patients a slightly impaired ejection fraction of $40-50 \%$ was found $(83.9 \%$ vs. $94.4 \%$ of patients, respectively; $\mathrm{p}=0.16$ ). Both study groups showed no difference in further pharmacological therapy, in particular in the prescription of statins or ACE inhibitors (Table 2).

\section{ENDOTHELIAL FUNCTION AND CULPRIT VESSEL PATENCY}

Measurement of endothelial function in the total patient population revealed an RH-PAT index of $1.90 \pm 0.58$. Patients with culprit vessel patency prior to PPCI had a significantly better endothelial 
Table 2. Patient characteristics, risk factors, and medication at discharge in the two study groups.

\begin{tabular}{|c|c|c|c|}
\hline Variables & $\begin{array}{c}\text { Patients with } \\
\text { initially non-patent } \\
\text { vessel }(n=38)\end{array}$ & $\begin{array}{l}\text { Patients with } \\
\text { initially patent } \\
\text { vessel }(n=33)\end{array}$ & $p$-value \\
\hline Men & $32(84.2)$ & $23(69.7)$ & \\
\hline Women & $6(15.8)$ & $10(30.1)$ & 0.1 \\
\hline Age, mean (SD) & $56.2(9.6)$ & $57.2(8.9)$ & 0.6 \\
\hline Smoker & $16(42.1)$ & $14(42.4)$ & \\
\hline Ex-smoker & $17(44.7)$ & $12(36.4)$ & \\
\hline Non-smoker & $5(13.2)$ & $7(21.2)$ & 0.6 \\
\hline BMI $\left(\mathrm{kg} / \mathrm{m}^{2}\right)$, mean $(S D)^{*}$ & $28.6(3.1)$ & $28.1(5.4)$ & 0.6 \\
\hline $\mathrm{BMI}<25 \mathrm{~kg} / \mathrm{m}^{2}$ & $4(10.8)$ & $7(21.2)$ & \\
\hline BMI $25<30$ kg/m² & $22(59.5)$ & $18(54.4)$ & \\
\hline $\mathrm{BMI} \geq 30 \mathrm{~kg} / \mathrm{m}^{2}$ & $11(29.7)$ & $8(24.2)$ & 0.5 \\
\hline Diabetes & $6(15.8)$ & $4(12.1)$ & 0.7 \\
\hline Hypercholesterolaemia & $10(26.3)$ & $7(21.2)$ & 0.6 \\
\hline Hypertension & $10(26.3)$ & $9(27.3)$ & 0.9 \\
\hline Acetylsalicylic acid** & 34 (94.4) & $31(96.9)$ & 0.6 \\
\hline Clopidogrel** & $34(94.4)$ & $29(90.6)$ & 0.5 \\
\hline Beta-blocker** & $31(81.6)$ & $27(84.4)$ & 0.8 \\
\hline Oral anticoagulant** & $2(5.6)$ & $1(3.1)$ & 0.6 \\
\hline ACE inhibitor** & $16(44.4)$ & $17(53.1)$ & 0.5 \\
\hline$A R B^{* *}$ & $6(16.7)$ & $3(9.4)$ & 0.4 \\
\hline Calcium channel blocker** & $8(22.2)$ & $4(12.5)$ & 0.3 \\
\hline Statin** & $34(94.4)$ & $30(93.8)$ & 0.9 \\
\hline \multicolumn{4}{|c|}{$\begin{array}{l}\text { Values are n (\%) unless otherwise specified. *one missing value, **three missing values. } \\
\text { p-values were derived from chi-square test for categorical variables and t-test for } \\
\text { continuous variables. ACE: angiotensin-converting enzyme; ARB: angiotensin receptor } \\
\text { blocker; BMI: body mass index }\end{array}$} \\
\hline
\end{tabular}

function than patients with occluded culprit vessels at presentation (RH-PAT index $2.08 \pm 0.34$ vs. $1.75 \pm 0.35$, $\mathrm{p}=0.007$ ). Two case examples are shown in Figure 1. Assessment of potential relations between RH-PAT index and various patient demographics and cardiovascular risk factors showed a trend towards better endothelial function in women, non-smokers, and patients with hypertension (Table 3). Patients with a BMI $<25 \mathrm{~kg} / \mathrm{m}^{2}$ showed a better endothelial function $(\mathrm{p}=0.01)$, while there was no significant relation between endothelial function and patients with diabetes $(p=0.5)$ (Table 3). Even when HbA1c levels at six weeks were used, no significance was achieved $(\mathrm{p}=0.65)$.
Table 3. Patient characteristics, risk factors, and association with endothelial function.

\begin{tabular}{|c|c|c|c|}
\hline Variables & $\begin{array}{c}\text { RH-PAT index } \\
\text { Mean (SD) }\end{array}$ & $\begin{array}{c}\text { Mean difference } \\
\text { (95\% CI) }\end{array}$ & p-value** \\
\hline Overall $(n=71)$ & $1.90(0.58)$ & & \\
\hline Men $(n=55)$ & $1.86(0.50)$ & & \\
\hline Women $(n=16)$ & $2.07(0.78)$ & $-0.21(-0.65-0.22)$ & 0.3 \\
\hline Age & $0.18^{*}$ & & 0.2 \\
\hline Smoker $(n=30)$ & $1.88(0.56)$ & & \\
\hline Ex-smoker $(n=29)$ & $1.83(0.55)$ & & \\
\hline Non-smoker $(n=12)$ & $2.13(0.67)$ & & 0.3 \\
\hline $\mathrm{BMI}<25\left(\mathrm{~kg} / \mathrm{m}^{2}\right)(\mathrm{n}=14)$ & $2.42(0.96)$ & & \\
\hline BMI $25<30\left(\mathrm{~kg} / \mathrm{m}^{2}\right)(\mathrm{n}=39)$ & $1.77(0.42)$ & & \\
\hline $\mathrm{BMI} \geq 30\left(\mathrm{~kg} / \mathrm{m}^{2}\right)(\mathrm{n}=18)$ & $1.90(0.42)$ & & 0.01 \\
\hline Diabetes $(n=10)$ & $1.78(0.38)$ & & \\
\hline No diabetes $(n=61)$ & $1.92(0.60)$ & $0.14(-0.25-0.53)$ & 0.5 \\
\hline Hypercholesterolaemia $(n=17)$ & $1.90(0.53)$ & & \\
\hline No hypercholesterolaemia $(n=54)$ & $1.90(0.60)$ & $-0.01(-0.33-0.31)$ & 1.0 \\
\hline Hypertension ( $n=19$ ) & $2.02(0.52)$ & & \\
\hline No hypertension ( $n=52$ ) & $1.86(0.60)$ & $0.16(-0.15-0.46)$ & 0.3 \\
\hline $\begin{array}{l}{ }^{*} \text { Pearson correlation coefficient. }{ }^{* *} \\
\text { mass index }\end{array}$ & lue of t-test, one & way ANOVA, or Pear & n. BMI: body \\
\hline
\end{tabular}

The results of the assessment of the relation between endothelial function and culprit vessel patency are presented in Table 4. The relation between endothelial function and patency of the culprit vessel (OR 5.1) became stronger when adjusting for sex and age (OR 5.4), and when adjusting for all other cardiovascular risk factors and for time interval between symptom onset and PPCI (OR 6.7).

\section{Discussion}

In this prospective pilot study in STEMI patients, a better endothelial function was strongly and independently associated with patency of the culprit artery at presentation, prior to any mechanical intervention. Even when adjusting for age, gender, and various other cardiovascular risk factors, this relation remained strong. Logistic regression analysis demonstrated that the time interval between symptom onset and PPCI did not disturb the relationship between endothelial function and patency of the culprit artery; this relationship had so far not been demonstrated.

Table 4. Endothelial function and adjusted risk of a non-patent culprit vessel at initial presentation.

\begin{tabular}{|c|c|c|c|c|c|c|}
\hline & $\begin{array}{l}\text { Non-patent culprit } \\
\text { vessel n (\%) }\end{array}$ & $\begin{array}{c}\text { Patent culprit vessel } \\
\mathbf{n}(\%)\end{array}$ & $\begin{array}{l}\text { OR, unadjusted } \\
\text { (95\% CI) }\end{array}$ & $\begin{array}{l}\text { OR, adjusted for sex } \\
\text { and age ( } 95 \% \mathrm{CI})\end{array}$ & $\begin{array}{l}\text { OR, adjusted } \\
\text { (95\% CI)* }\end{array}$ & $\begin{array}{l}\text { OR, adjusted } \\
(95 \% \text { Cl)** }\end{array}$ \\
\hline RH-PAT Index $<1.67$ & $25(65.8)$ & $9(27.3)$ & $5.1(1.8-14.2)$ & $5.4(1.9-15.9)$ & $7.1(2.1-23.6)$ & $6.7(1.6-28.4)$ \\
\hline $\begin{array}{l}\text { RH-PAT Index } \geq 1.67 \\
\text { (good endothelial function) }\end{array}$ & $13(34.2)$ & $24(72.7)$ & 1 (Reference) & 1 (Reference) & 1 (Reference) & 1 (Reference) \\
\hline Overall & 38 & 33 & & & & \\
\hline
\end{tabular}

Non-patent culprit vessel was defined as TIMI flow grade 0-1. Patent culprit vessel was defined as TIMI flow grade 2-3. *adjusted for sex, age, smoking, diabetes, body mass index, hypertension and hypercholesterolaemia ( $\mathrm{n}=70 ; 1$ missing value $\mathrm{BMI}$ ) **adjusted for sex, age, smoking, diabetes, body mass index, hypertension and hypercholesterolaemia and time to PPCl ( $n=62 ; 1$ missing BMl and 8 missing time to PPCI) Cl: confidence interval; OR: odds ratio 
In the setting of STEMI, thrombus formation on ruptured or fissured atherosclerotic plaques obstructs the lumen, which, augmented by vasoconstriction, generally leads to occlusion of the lumen. In the presence of developing thrombus, endogenous fibrinolysis is rapidly initiated by the local endothelium that tightly regulates plasmin generation, fibrin degradation, and dissolution of the thrombus ${ }^{18,19}$. As a result, thrombus growth is limited and reperfusion is promoted; however, the efficacy of this system depends on functional endothelium ${ }^{20,21}$

Endothelial dysfunction, on the other hand, disturbs various homeostatic pathways and predisposes to vasoconstriction, platelet activation, and thrombus formation ${ }^{4,18}$. As a result, endothelial dysfunction limits the endogenous fibrinolytic capacity and the likelihood of restoring vessel patency in the setting of an acute myocardial infarction, which can occur spontaneously in up to $30 \%$ of STEMI patients within the first 12 hours ${ }^{21-24}$. In keeping with this, the endothelial fibrinolytic capacity, as measured by the release of the fibrinolytic factor tissue plasminogen activator, has been found to predict the risk of future adverse cardiovascular events in patients with initially stable coronary heart disease ${ }^{18}$. Moreover, Lerman et al have shown that endothelial dysfunction is related to a higher incidence of consecutive acute coronary syndromes ${ }^{25,26}$.

Ideally, one would like to analyse endothelial function data which were obtained directly before the STEMI occurred ${ }^{27}$. In general, no such data are available, and endothelial function measurements from the acute phase of a STEMI may not reflect well the endothelial function prior to the STEMI. PPCI itself has been shown to induce a systemic endothelial dysfunction and a systemic inflammatory response that peaks at 24-48 hours before it gradually decreases ${ }^{28,29}$. To prevent such disturbance of endothelial function that may also be affected by myocardial infarction size, we performed the measurements after four to six weeks from the PPCI. The process of "myocardial repair" may be largely finished after three weeks, which comes close to the time that we started endothelial function measurements in the present study. The stabilisation of endothelial function, and the reduction in inflammatory response and hypercoagulability, which have then occurred, may also account for the superior clinical outcome of STEMI patients who underwent PCI of non-culprit vessel(s) with some delay (i.e., within two months after the initial hospitalisation), as compared to patients in whom multivessel treatment was performed directly during the initial hospitalisation (data from the Western Denmark Heart Registry) ${ }^{30}$. Nevertheless, certain (high-risk) STEMI patients require treatment of multiple coronary arteries during the initial hospitalisation, which can be performed with an acceptable in-hospital mortality ${ }^{31}$

Only one other study has also investigated endothelial function in survivors of STEMI, as was done in our study. In 29 young STEMI patients (age $<40$ years), Chen et al assessed flow-mediated vasodilation of the brachial artery and found more endothelial dysfunction with higher age ${ }^{32}$. In the present study, we examined 71 STEMI patients with a mean age of 57 years (ranging from 38 to 76 years) with the RH-PAT method to investigate a different research issue.
The relation between endothelial function and coronary flow has been more frequently studied outside the setting of acute coronary syndromes and in the absence of obstructive coronary disease $\mathrm{e}^{33,34}$. Slow coronary flow, which is defined as delayed coronary opacification in the absence of obstructive coronary lesions, is often the result of microvascular constriction that is caused by endothelial dysfunction $^{35}$. Male sex, younger age, smoking, high BMI, and features of metabolic syndrome were found to be associated with slow coronary flow ${ }^{35-37}$.

\section{Limitations}

We cannot exclude that the sample size of our study population could have masked certain relations between cardiovascular risk factors and endothelial function. For that reason, we liberally included various patient characteristics and cardiovascular risk factors in the logistic regression model, which demonstrated an even stronger relation between initial vessel patency and endothelial function. Nevertheless, because of the limited sample size, further studies are required to confirm our hypothesis-generating findings. While it is true that endothelial function measurements after some weeks do not necessarily reflect the endothelial function at the time of STEMI, an earlier timing of endothelial function measurements would have implied a significant risk of disturbance from the inflammation that is associated with "myocardial repair" following STEMI. Endothelial function was measured about four weeks after the acute event when all patients were treated with a similar secondary preventive medication that included statins and frequently ACE inhibitors, which might have had favourable effects on endothelial function (in both study groups); nevertheless, there was no significant difference in medical treatment between groups.

\section{Conclusion}

In this series of patients with acute STEMI, a better endothelial function was independently associated with a higher likelihood of initial culprit vessel patency, prior to any mechanical intervention.

\section{Impact on daily practice}

Patients with acute STEMI, who initially present with patent culprit coronary arteries, are known to have, on average, superior clinical outcomes. Functional endothelium is likely to promote early culprit vessel patency, but clinical data on that relationship are very scarce. The present prospective cohort study is the first to demonstrate that, compared to patients with normal endothelial function, patients with severe endothelial dysfunction have a much higher risk of presenting with an occluded culprit vessel prior to any mechanical intervention. This finding underlines the importance of measures to improve endothelial function in patients at increased cardiovascular risk, as improvement in endothelial function, besides reducing the overall risk of having a STEMI, is likely to increase the chance of early culprit vessel patency in STEMI patients. 


\section{Funding}

This investigator-initiated, non-funded observational study was performed in a single-centre STEMI patient population that was also enrolled in the RESPONSE multicentre trial, funded by AstraZeneca.

\section{Conflict of interest statement}

C. von Birgelen is a consultant to and/or has received lecture fees or travel expenses from Abbott Vascular, Boston Scientific, and Medtronic, and has received speaker's honoraria from MSD. The research department of Thoraxcentrum Twente has received educational and/or research grants from Abbott Vascular, Biotronik, Boston Scientific, and Medtronic. R. Peters is a consultant to AstraZeneca. The other authors have no conflicts of interest to declare.

\section{References}

1. Birkemeyer R, Rillig A, Treusch F, Koch A, Miljak T, Meyerfeldt U, Kunze M, Jung W, Höher M. Abortion of myocardial infarction by primary angioplasty mainly depends on preprocedural TIMI flow. EuroIntervention. 2011;6:854-9.

2. Vanhoutte PM, Shimokawa H, Tang EH, Feletou M. Endothelial function and vascular disease. Acta Physiol (Oxf). 2009;196:193-222.

3. Herrmann J, Kaski J, Lerman A. Coronary microvascular dysfunction in the clinical setting: from mystery to reality. Eur Heart J. 2012;33:2771-2782b.

4. Lerman A, Holmes D, Herrmann J, Gersh B. Microcirculatory dysfunction in ST-elevation myocardial infarction: cause, consequence, or both? Eur Heart J. 2007;28:788-97.

5. Anderson TJ, Uehata A, Gerhard MD, Meredith IT, Knab S, Delagrange D, Lieberman EH, Ganz P, Creager MA, Yeung AC, et al. Close relation of endothelial function in human coronary and peripheral circulations. J Am Coll Cardiol. 1995;26:1235-41.

6. Neunteufl T, Katzenschlager R, Hassan A, Klaar U, Schwarzacher S, Glogar D, Bauer P, Weidinger F. Systemic endothelial dysfunction is related to the extent and severity of coronary artery disease. Atherosclerosis. 1997;129:111-8.

7. Patvardhan EA, Heffernan KS, Ruan JM, Soffler MI, Karas RH, Kuvin JT. Assessment of vascular endothelial function with peripheral arterial tonometry: information at your fingertips? Cardiol Rev. 2010;18:20-8.

8. Kuvin JT, Patel AR, Sliney KA, Pandian NG, Sheffy J, Schnall RP, Karas RH, Udelson JE. Assessment of peripheral vascular endothelial function with finger arterial pulse wave amplitude. Am Heart J. 2003;146:168-74.

9. Kandhai-Ragunath JJ, Jørstad HT, de Man FH, Peters RJ, von Birgelen C. Approaches for non-invasive assessment of endothelial function: focus on peripheral arterial tonometry. Neth Heart $J$. 2013;21:214-8.

10. Jorstad HT, von Birgelen C, Alings AM, Liem A, van Dantzig JM, Jaarsma W, Lok DJ, Kragten HJ, de Vries K, de Milliano PA, Withagen AJ, Scholte Op Reimer WJ, Tijssen JG,
Peters RJ. Effect of a nurse-coordinated prevention programme on cardiovascular risk after an acute coronary syndrome: main results of the RESPONSE randomised trial. Heart. 2013;99:1421-30.

11. The Thrombolysis in Myocardial Infarction (TIMI) trial. Phase I findings. TIMI Study Group. NEngl JMed. 1985;312:932-6.

12. Comparison of invasive and conservative strategies after treatment with intravenous tissue plasminogen activator in acute myocardial infarction. Results of the thrombolysis in myocardial infarction (TIMI) phase II trial. The TIMI Study Group. $N$ Engl $J$ Med. 1989;320:618-27.

13. Nohria A, Gerhard-Herman M, Creager MA, Hurley S, Mitra D, Ganz P. Role of nitric oxide in the regulation of digital pulse volume amplitude in humans. J Appl Physiol. 2006;101:545-8.

14. Bonetti PO, Pumper GM, Higano ST, Holmes DR Jr, Kuvin JT, Lerman A. Noninvasive identification of patients with early coronary atherosclerosis by assessment of digital reactive hyperemia. J Am Coll Cardiol. 2004;44:2137-41.

15. Hamburg NM, Keyes MJ, Larson MG, Vasan RS, Schnabel R, Pryde MM, Mitchell GF, Sheffy J, Vita JA, Benjamin EJ. Crosssectional relations of digital vascular function to cardiovascular risk factors in the Framingham Heart Study. Circulation. 2008; 117:2467-74.

16. Brant LC, Barreto SM, Passos VM, Ribeiro AL. Reproducibility of peripheral arterial tonometry for the assessment of endothelial function in adults. J Hypertens. 2013;31:1984-90.

17. Selamet Tierny ES, Newburger JW, Gauvreau K, Geva J, Coogan E, Colan SD, de Ferranti SD. Endothelial pulse amplitude testing: feasibility and reproducibility in adolescents. $J$ Pediatr. 2009; 154:901-5.

18. Robinson SD, Ludlam CA, Boon NA, Newby DE. Endothelial fibrinolytic capacity predicts future adverse cardiovascular events in patients with coronary heart disease. Arterioscler Thromb Vasc Biol. 2007;27:1651-6.

19. Emeis JJ. Regulation of the acute release of tissue-type plasminogen activator from the endothelium by coagulation activation products. Ann N Y Acad Sci. 1992;667:249-58.

20. Hrafnkelsdottir T, Gudnason T, Wall U, Jern C, Jern S. Regulation of local availability of active tissue-type plasminogen activator in vivo in man. $J$ Thromb Haemost. 2004;2:1960-8.

21. Oliver JJ, Webb DJ, Newby DE. Stimulated tissue plasminogen activator release as a marker of endothelial function in humans. Arterioscler Thromb Vasc Biol. 2005;25:2470-9.

22. DeWood MA, Spores J, Notske R, Mouser LT, Burroughs R, Golden MS, Lang HT. Prevalence of total coronary occlusion during the early hours of transmural myocardial infarction. $N$ Engl $J$ Med. 1980;303:897-902.

23. Armstrong PW, Baigrie RS, Daly PA, Haq A, Gent M, Roberts RS, Freeman MR, Burns R, Liu P, Morgan CD. Tissue plasminogen activator: Toronto (TPAT) placebo-controlled randomized trial in acute myocardial infarction. $\mathrm{J} \mathrm{Am} \mathrm{Coll} \mathrm{Cardiol.}$ 1989;13:1469-76.

24. Rentrop K, Feit F, Sherman W, Thornton J. Serial angiographic assessment of coronary artery obstruction and collateral 
flow in acute myocardial infarction. Report from the second Mount Sinai-New York University Reperfusion Trial. Circulation. 1989;80:1166-75.

25. Rubinshtein R, Kuvin JT, Soffler M, Lennon RJ, Lavi S, Nelson RE, Pumper GM, Lerman LO, Lerman A. Assessment of endothelial function by non-invasive peripheral arterial tonometry predicts late cardiovascular adverse events. Eur Heart J. 2010;31:1142-8.

26. Suwaidi JA, Hamasaki S, Higano ST, Nishimura RA, Holmes DR Jr, Lerman A. Long-term follow-up of patients with mild coronary artery disease and endothelial dysfunction. Circulation. 2000;101:948-54.

27. Akcakoyun M, Kargin R, Tanalp AC, Pala S, Ozveren O, Akcay M, Barutcu I, Kirma C. Predictive value of noninvasively determined endothelial dysfunction for long-term cardiovascular events and restenosis in patients undergoing coronary stent implantation: a prospective study. Coron Artery Dis. 2008;19:337-43.

28. Warnholtz A, Ostad MA, Heitzer T, Goldmann BU, Nowak G, Munzel T. Effects of tirofiban on percutaneous coronary intervention-induced endothelial dysfunction in patients with stable coronary artery disease. Am J Cardiol. 2005;95:20-3.

29. Azar RR, McKay RG, Kierman FJ, Seecharan B, Feng YJ, Fram DB, Wu AH, Waters DD. Coronary angioplasty induces a systemic inflammatory response. Am J Cardiol. 1997;80:1476-8.

30. Jensen LO, Thayssen P, Farkas DK, Hougaard M, Terkelsen CJ, Tilsted HH, Maeng M, Junker A, Lassen JF, Horváth-Puhó E, Sørensen HT, Thuesen L. Culprit only or multivessel percutaneous coronary interventions in patients with ST-segment elevation myocardial infarction and multivessel disease. EuroIntervention. 2012;8:456-64.

31. Jaguszewski M, Radovanovic D, Nallamothu BK, Lüscher TF, Urban P, Eberli FR, Bertel O, Pedrazzini GB, Windecker S, Jeger R, Erne P; AMIS Plus Investigators. Multivessel versus culprit vessel percutaneous coronary intervention in ST-elevation myocardial infarction: is more worse? EuroIntervention. 2013;9: 909-15.

32. Chen SM, Tsai TH, Hang CL, Yip HK, Fang CY, Wu CJ, Guo GB. Endothelial dysfunction in young patients with acute ST-elevation myocardial infarction. Heart Vessels. 2011;26:2-9.

33. Sezgin AT, Sigirci A, Barutcu I, Topal E, Sezgin N, Ozdemir R, Yetkin E, Tandogan I, Kosar F, Ermis N, Yologlu S, Bariskaner E, Cehreli S. Vascular endothelial function in patients with slow coronary flow. Coron Artery Dis. 2003;14:155-61.

34. Tanriverdi H, Evrengul H, Kuru O, Tanriverdi S, Seleci D, Enli Y, Kaftan HA, Kilic M. Cigarette smoking induced oxidative stress may impair endothelial function and coronary blood flow in angiographically normal coronary arteries. Circ J. 2006;70:593-9.

35. Yilmaz H, Demir I, Uyar Z. Clinical and coronary angiographic characteristics of patients with coronary slow flow. Acta Cardiol. 2008;63:579-84.

36. Beltrame JF, Limaye SB, Horowitz JD. The coronary slow flow phenomenon--a new coronary microvascular disorder. Cardiology. 2002;97:197-202.

37. Hawkins BM, Stavrakis S, Rousan TA, Abu-Fadel M, Schechter E. Coronary slow flow--prevalence and clinical correlations. Circ J. 2012;76:936-42. 